\title{
Letters
}

\section{Medical involvement in torture}

SIR

Regarding the debate surrounding medical involvement in torture and the articles by Professors R S Downie and $R$ M Hare (1): We have learned from Ayn Rand that when a discussion gets bogged down, one should check one's premises. First, let me offer my definition of torture. To torture is to inflict suffering on another to alter his or her mindset. One should comment parenthetically that the word torture is used at times to emphasize the severity of inflicted suffering, but this is a borrowed sense. The essence of the meaning is contained in the definition above.

In their articles, Professors Downie and Hare recognize in an inchoate manner that doctoring is special. I should like to propose that the distinction is not in the person but in the contract. The Hippocratic oath is the contract between the doctor and his patient '... to serve to the best of my ability' in return for payment. This is a special case of contract between free men. The law of contract is enshrined in our free society in the English common law and in the American Constitution. The doctor is serving his patient to the best of his ability. The essence of a man is his independent mind. It becomes evident, as a tautology, that torture can never be inflicted within the terms of this contract. So, what of the scenario Professor Hare offers us of a terrorist who has put a bomb in a litter-bin in a crowded place? This is a special case where the duty of the government is to protect the public. A doctor in the service of the state, and being an agent of the state, might be called upon to be associated in the torture of the terrorist in this scenario. Should the doctor plead that because he has a degree in medicine he is too pure to share in what is essentially a military operation for the well-being of society? Does the term doctor confer upon us the hypocrisy of a conscientious objector when one's country is at war? No. I propose to you that a doctor working for the state is in no way superior or purer than any other agent of government. The veterinarian servicing the farmer's herd can help his patients because the health of the animal usually coincides with the needs of the farmer. The line of authority runs, however, from farmer through veterinarian. In the platonic role a doctor who is a government employee acts; the line of authority is the same. The confusion arose, therefore, from failure to realize that the unique aspect of doctoring is in the contract and not the person.

Ayn Rand used the term package deal to signal the introduction of a concept into a discussion by implication. This is the situation we are living through in America on a grand scale. The dialectic raging regarding health care is how to make all doctors work for the state (the platonic relationship). Unfortunately, we are not hearing any discussion about whether they should. Elsewhere in the same issue of your journal in The Hippocratic Contract, J Rosalki (2) makes a similar mistake in implying that a contract can have a unilateral purpose. The morals of our great profession have been predicated on a free contract between patient and doctor. The socialist disruption of this relationship should not be tolerated 'in the spirit of our time' but resisted firmly to resist corruption of doctoring.

\section{References}

(1) Downie $\mathrm{R} S$. The ethics of medical involvement in torture. fournal of medical ethics 1993; 3: 135-137. Hare R M. The ethics of medical involvement in torture: commentary. Fournal of medical ethics 1993; 3: 138-140.
(2) Rosalki J. The Hippocratic contract. Fournal of medical ethics 1993; 3: 154-156.

THOMAS A DORMAN, MB, ChB, MRCP(UK), FRCP(C) $171 N$ Santa Rosa Street, Suite A, San Luis Obispo, California 93405-1322, USA.

\section{Genetic counselling}

SIR

The question of what counts as success in genetic counselling is discussed by Chadwick (1) and Clarke (2). They agree that measuring the effectiveness of genetic counselling by number of termination of pregnancies is inappropriate.

Clarke suggests an alternative outcome measure of workload, but Chadwick regards this as inadequate. She also considers the 'right to choose' (or autonomy) to be an inadequate outcome measure. Autonomy is a process rather than an outcome. It is a means to an end. But what end?

She says that one cannot avoid the question of 'what is the objective of genetic counselling'? It is, she suggests, to give options that may improve the genetic health of individuals, thereby improving the genetic health of the population. This is not eugenics, in that the population result is a by-product of giving choice, albeit a restricted choice, to individuals, rather than a government policy. In order to avoid any possibility of hidden coercion, Chadwick suggests that the objective of genetic health be explicitly stated.

Giving choice is not a neutral activity. It involves giving information, and giving information is of necessity selective. What information is given, and how it is presented, is influenced by certain factors, for example, counsellors' beliefs about the objectives of counselling and how to achieve 'non-directiveness'. 